\title{
ARMAS Y POLÍTICA EN LA ARGENTINA. \\ TUCUMÁN, SIGLO XIX
}

de Flavia Macías,

Madrid, CSIC, 2014, 285 págs.

LAURA CUCCHI

Instituto de Historia Argentina y Americana

«Dr. Emilio Ravignani» Universidad de

Buenos Aires/CONICET

Este libro, que forma parte de la mica político-institucional de cada una Colección América del Consejo Superior de las provincias.

de Investigaciones Científicas de España, El tópico elegido por Macías para aborconstituye una versión revisada y am- dar esas transformaciones es el de las dipliada de la tesis doctoral defendida por Flavia Macías en 2007 en la Universidad Nacional de La Plata. En palabras de su autora, el principal objetivo del libro es examinar la relación entre la violencia y la construcción del sistema político argentino, poniendo el foco en la experiencia de Tucumán y la región del Norte. En ese sentido, la obra dialoga con la historiografía que en los últimos años se ha propuesto revisar el problema de la construcción del Estado nacional a partir de las negociaciones y confrontaciones específicas que este proceso implicó en cada uno de los espacios provinciales y regionales, y que lo hace a través del estudio de las vinculaciones entre la edificación de una autoridad de alcance nacional y la dináversas formas en que se organizó la fuerza pública en Tucumán entre 1830 y 1880, especialmente «el tránsito del Ejército Provincial al Ejército Nacional» (p. 28). Esa elección temática permite echar una mirada a tres problemas centrales de los diferentes ensayos de organización política que tuvieron lugar en el siglo XIX: por una parte, a la cuestión de las incumbencias militares y los conflictos por el control de la fuerza entre las provincias, o entre ellas y las autoridades supraprovinciales. En segundo lugar, al rol que esas fuerzas jugaron en las luchas políticas provinciales, regionales, nacionales e internacionales como la Guerra del Paraguay. Por último, el hecho de que estuvieran compuestas por cuerpos profesionales (el Ejército de 
Línea) y ciudadanos (milicias provinciales y Guardia Nacional), brinda un mirador para analizar las controversias decimonónicas sobre cuál era el formato militar más apropiado para una república y sobre cuáles constituían en ese marco los contornos de los deberes y derechos ciudadanos.

El libro está compuesto de cuatro capítulos-seguidos de un anexo documentalque abordan respectivamente la etapa de una laxa confederación de estados provinciales entre 1832 y 1852 , la experiencia de la Confederación Argentina (1852-1861), la unificación de esta con el Estado de Buenos Aires y la presidencia de Mitre (1862-1868), y los años que siguieron a la Guerra del Paraguay hasta la llegada de Roca a la presidencia (1868-1880).

En el primero la autora examina la relación entre el poder de los gobernadores y el manejo de las milicias en el marco de la organización y consolidación de los estados provinciales durante el rosismo, momento en el cual las provincias contaban con la atribución de poseer ejércitos (formados a partir de la reorganización de las milicias de la etapa revolucionaria) y declarar la guerra. El foco del capítulo está puesto en los diferentes equilibrios de poder entablados en Tucumán entre el gobernador, la Legislatura, las milicias urbanas y los cuerpos de campaña durante la gobernación de Alejandro Heredia, la etapa de la Coalición del Norte contra Rosas y el mandato de Celedonio Gutiérrez. Allí atiende a las características de los conflictos armados en la provincia y a su relación con las disputas político-militares regionales, en un formato de análisis que se repite a lo largo del libro y que resulta una perspectiva de análisis muy acertada.

En el segundo capítulo, Macías revisita la experiencia de la Confederación Argentina y la secesión de Buenos Aires en los años cincuenta, periodo que últimamente ha recibido renovada atención historiográfica. En esta sección el estudio aborda los desafíos políticos e institucionales que trajo el proyecto de Urquiza de dejar atrás la configuración militar descentralizada propia de los años del rosismo, y avanzar hacia la conformación de un Ejército Nacional. Esta transformación implicaba la difícil tarea de incorporar las fuerzas militares de las provincias y ponerlas bajo el mando de una autoridad nacional, problema que se proyectó al menos hasta 1880 . Como parte de ese proyecto, se crearon también las Comandancias Militares con el objetivo de subordinar a los gobernadores a los Coroneles de la Nación.

No obstante, como muestran el segundo y tercer capítulo, esas iniciativas centralizadoras se toparon con dos dificultades: por una parte, con la creciente injerencia de esos oficiales nacionales en los conflictos políticos provinciales y regionales, lo cual contribuyó a la desestabilización política del interior. Por otra, 
con los obstáculos para la centralización militar que trajo el hecho de que los gobernadores conservaran prerrogativas en materia de organización y movilización de la Guardia Nacional con sede en las provincias. Pues, como señala la autora, aunque la Constitución estipulara que los gobernadores organizaban las Guardias Nacionales pero sólo el poder central podía movilizarlas, mencionaba también que los mandatarios provinciales podían hacerlo en caso de peligro inminente. Este intersticio normativo fue a menudo condenado por los poderes nacionales, quienes sin embargo lo utilizaron en ocasiones para imponer su autoridad en el interior de la mano de aliados (como en el caso de Mitre y los Taboada), lo cual potenció los conflictos regionales.

Como bien muestra el estudio de Macías, las iniciativas de centralización en materia militar también tuvieron lugar en el interior de las provincias que, simultáneamente a la Nación, estaban buscando organizar sus sistemas institucionales. Allí la tarea radicó en reorganizar las milicias provinciales en nuevas estructuras militares. En la ciudad, las guardias nacionales (empadronadas en base al domicilio y ya no en base a criterios socio-profesionales) reemplazaron a los cuerpos cívicos de la etapa preconstitucional, junto con el Piquete de línea, una fuerza veterana de servicio regular y dependiente del Ministerio de Guerra de la Nación que custodiaba el armamento. Mientras que también en los departamentos de campaña se recortó progresivamente el margen de autonomía de los antiguos comandantes de la mano de la creación y consolidación de la Gendarmería Provincial. Esta innovación, junto con la sanción de un reglamento de Policía en 1877, sentó las bases para el fortalecimiento y burocratización de la fuerza que debía guardar el orden público en la provincia. De esta manera, las tareas de policía se sacaron del ámbito de las antiguas milicias ciudadanas y se pusieron bajo el dominio del estado, en un intento de despolitizar la fuerza pública que siguió caminos similares en varias provincias.

Este objetivo de centralización y consolidación del poder del estado en materia militar constituyó un pilar del mandato de Sarmiento, continuado durante la gestión de Avellaneda, que la autora explora en el último capítulo. Entonces se buscó avanzar en esa dirección con la profesionalización del Ejército de Línea de la mano de la creación del Colegio Militar y la Escuela Naval Militar. Al mismo tiempo, el Poder Ejecutivo Nacional procuró desarticular los liderazgos militares regionales para imponer un vínculo directo entre gobernadores y poder central, y romper así con la lógica de conflictos interprovinciales. También persiguió la despolitización de las milicias apartándolas de los procesos electorales. Desde 
1863 hasta 1877 era necesario estar enrolado en la Guardia Nacional para poder votar. Ese cuerpo se convirtió de ese modo en expresión de la "ciudadanía en armas», materializando una dimensión militar de la soberanía popular, y como tal protagonizó las disputas políticas que en Tucumán llegaron al terreno de las armas. Esa práctica "revolucionaria», que en nombre de una soberanía popular burlada se alzaba contra las «autoridades despóticas", alimentó los debates respecto de los contornos de las fuerzas militares y del lugar de los ciudadanos en ellas. En sintonía con propuestas recientes de Hilda Sabato, Macías sugiere que en esas polémicas se enfrentaron dos nociones de ciudadanía y de república: algunos entendieron que el servicio de armas era parte de las obligaciones que los ciudadanos debían cumplir como contracara de sus derechos. Otros postularon que el compromiso patriótico que el ciudadano asumía en la Guardia se hallaba por completo desvinculado de sus derechos electorales y que las dos esferas debían mantenerse escindidas. Esta postura triunfó en 1877 cuando se eliminó el requisito de estar enrolado para poder votar y en 1879 cuando se prohibieron los ejercicios doctrinales durante el periodo de inscripción en el Registro Cívico. Estas medidas nacionales para limitar la presencia de los guardias nacionales en cuanto tales en los comicios, se complementaron en Tucumán de la mano de la prohibición de que pudieran votar mientras se hallaran movilizados y de llevar armamento a las mesas de elecciones (1883). Junto con la prohibición de que las provincias formaran cuerpos militares bajo cualquier denominación sancionada durante la presidencia de Roca, inauguraron una nueva etapa en las discusiones sobre las características de las fuerzas militares. Según la autora, esta etapa se proyectó hasta la sanción de la ley Ricchieri de 1901 que fijó la conscripción obligatoria de todos los ciudadanos y terminó con la tradición de milicias ciudadanas, optando en cambio por un ejército regular, profesional y centralizado. En síntesis, este libro constituye un análisis en profundidad de un tema clave del siglo XIX como es la cuestión de la fuerza en la formación del sistema político, ofreciendo una mirada de medio siglo en un examen dinámico de las relaciones entre la dimensión provincial, la regional y la nacional. Con ese enfoque Ilumina el papel de las armas en la vida política decimonónica, atendiendo a las definiciones normativas, las prácticas y las representaciones que entonces se elaboraron sobre el modo que debía funcionar la fuerza pública, en especial la Guardia Nacional. Por estos motivos resulta una importante contribución para explicar el rol de esos cuerpos ciudadanos en la puesta en marcha del esquema republicano y federal diseñado por la Constitución, así como los desafíos y conflictos que ese proceso implicó. 